\title{
Infección experimental por Equinococcus granulosus en dos perros en la ciudad de Aguascalientes
}

Gómez-Torres J. R., Silva -Briano M** , Delgado-Guerrero E. G. ${ }^{* * *}$, Adabache-Ortiz A. ****

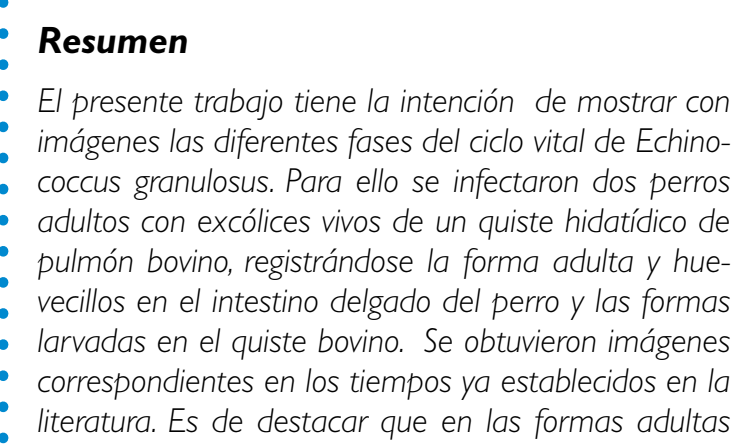

Palabras clave: Equinococcus granulosus, quiste hidatídico.

del parásito (son raros los especímenes en nuestro país) se tomaron imágenes con microscopía electrónica de barrido e hicimos un hallazgo, al demostrar la presencia de vellosidades en la superficie corporal del parásito, semejantes a un tubo digestivo. Por no encontrar en la literatura buscada, imágenes de ésta índole creemos que es importante y que debemos enfocarnos en este objetivo en un próximo estudio.

\section{Antecedentes}

El céstodo Echinococcus granulosus es el agente causal del quiste hidatídico ó hidatidosis reconocido como la mayor zoonosis a nivel mundial que afecta al ser humano y a los animales domésticos y silvestres ${ }^{1}$. El quiste hidatídico aparece principalmente en hígado y pulmón del huésped intermediario $^{2}$. Es una parasitosis frecuente en donde hay pastoreo de ganado y los perros

consumen sus vísceras crudas infectadas ${ }^{3}$. Von Siebold (1852) seguido por Haubner, Leuukart y Netttleship, alimentaron perros con escolices de quistes provenientes de animales domésticos y observaron que se desarrollaban gusanos adultos en perros, a partir de entonces se han hecho estudios de su morfología a detalle enfocadas principalmente a sus escolices ${ }^{4-6}$. En México se

\footnotetext{
* Profesor investigador del Departamento de Microbiología, Centro Básico. Universidad Autónoma de Aguascalientes, México.

** Profesor investigador del Departamento de Biología, Centro Básico. Universidad Autónoma de Aguascalientes, México.

*** Alumno de décimo semestre de la carrera de Medicina Universidad Autónoma de Aguascalientes, México

**** Bióloga, técnico auxiliar en el departamento de Biología de la Universidad Autónoma de Aguascalientes, México.
} 
han hecho pocos estudios ${ }^{7-9}$, sin embargo hay reportes del gusano adulto infectando perros en forma natural ${ }^{10} \mathrm{y}$ al parecer existen aisladamente en la literatura estudios realizados con microscopía electrónica de barrido y los que existen están enfocados a la descripción de formas larvarias en quiste hidatídico más que del gusano adulto ${ }^{11}$.
El objetivo del presente trabajo es demostrar, la presencia de un parásito poco reportado en nuestro país e iniciar un área de estudio y utilizar la herramienta visual disponible para mostrar una serie de imágenes poco difundidas que contribuyan a mayor conocimiento objetivo de este parásito en estudiantes de medicina.

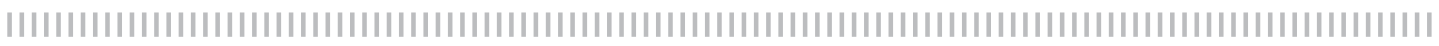

\section{Materiales y métodos}

A partir de un quiste bovino, se tomó una muestra de su contenido líquido donde se confirmó la presencia de arenilla hidatídica con microscopía (ver figura 1). A dos perros adultos se les administró $10 \mathrm{ml}$ de líquido del quiste en la cavidad bucal con una jeringa. Desde el inicio de la inoculación oral se efectuaron coproparasitoscópicos para detectar la presencia de huevecillos y demostrar que no existía previamente la infección en los perros. En la octava semana se detectaron al microscopio huevos que pudieran corresponder a E. granulosus . A la doceava semana, se sacrificó uno de los perros y se procedió a realizar una resección para extraer intestino delgado previa obturación en su extremo distal y proximal. Al duodeno se le practicó un corte longitudinal para su revisión macroscópica y colecta de especímenes. El otro perro murió con síntomas de intoxicación parasitaria. Los especímenes colectados se registraron vivos en video, otros se prepararon con tinciones rojo carmín y algunos se seleccionan para su limpieza mecánico-enzimática (digestión artificial) para su registro en Microscopía Electrónica de Barrido (MEB).

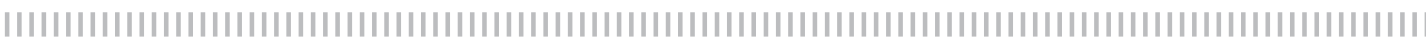

\section{Resultados}

La revisión microscópica del intestino delgado mostró la presencia de innumerables adultos de $0.3-0.4 \mathrm{~cm}$ de Echinococcus granulosus, los registrados vivos presentan movimientos peristálticos. (ver Figuras 1 y 2). Las figuras 3 y 4 presentaban tinciones con rojo carmín mostrando un gusano completo con el tercer proglótido repleto de huevecillos (Grávido). Las fotomicros-

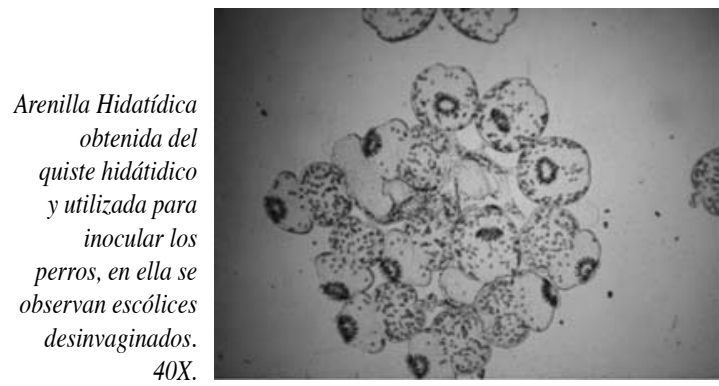

copias de barrido resaltan las estructuras del gusano completo en tres dimensiones y se observan algunos detalles de importancia como el escólex, con sus hileras de ganchos, y el acercamiento de uno de ellos (figuras. 5, 6, 7 y 8). En el resto de las imágenes llama la atención la presencia de numerosas estructuras cortas sumamente numerosas que semejan vellosidades del tubo digestivo de un mamífero.

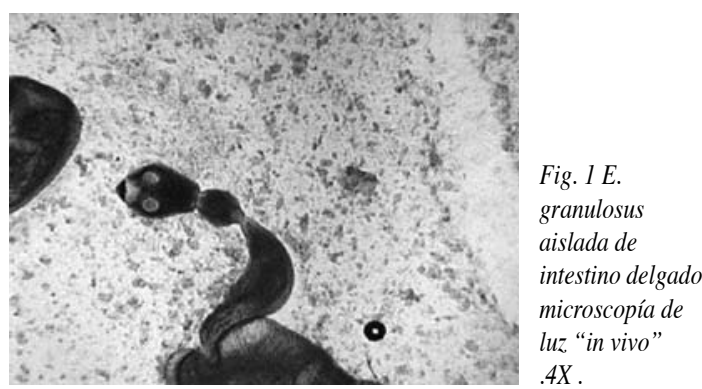

Número diez, sept-dic del 2008 LUX MIÉDICA 


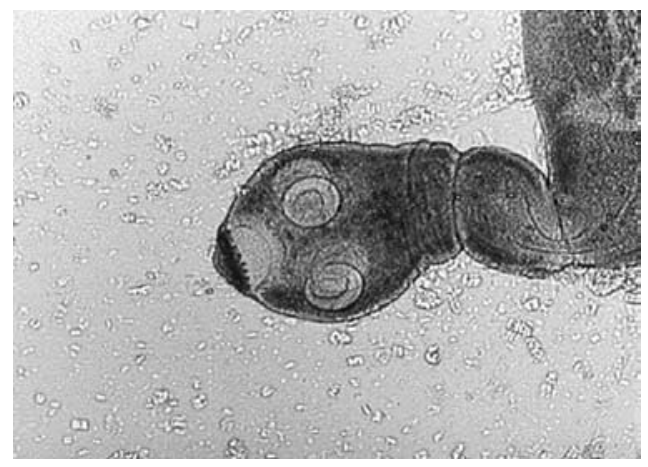

Fig. 2 E, granulosus "in vivo" Acercamiento mostrando el escólex notándose el conducto excretor .10X.

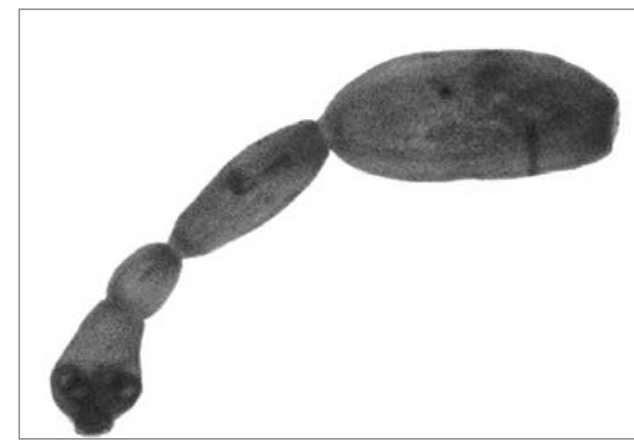

Fig. 3 E. granulosus Teñido con rojo carmín con los correspondientes segmentos Escólex proglótido inmaduro, maduro y grávido (proglótido fina). $4 X$.

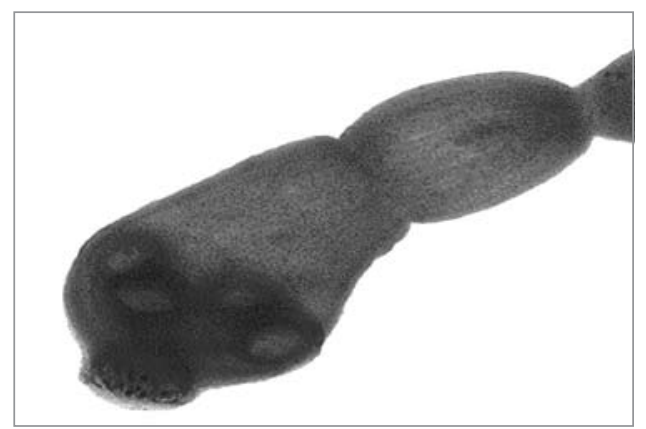

Fig. 4 Escólex de E. granulosus Teñido con rojo carmín. 10X.

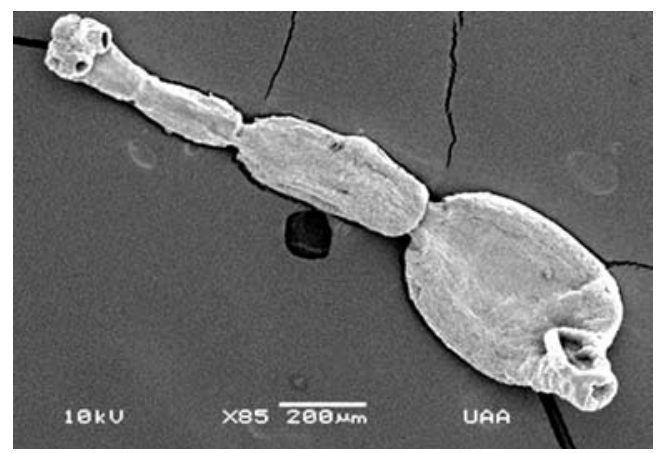

Fig.5 Espécimen completo de E. granulosus. MEB.

LUX MIÉDICA Número diez, sept-dic del 2008

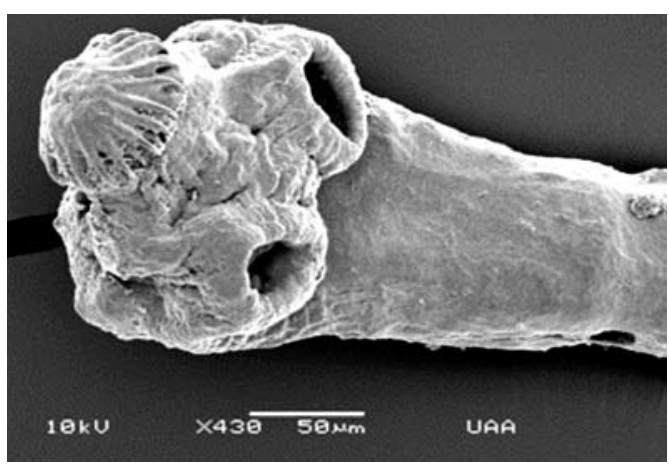

Fig. 6 Detalle del escólex de E. granulosus, resaltando la doble corona de ganchos y ventosas. MEB.

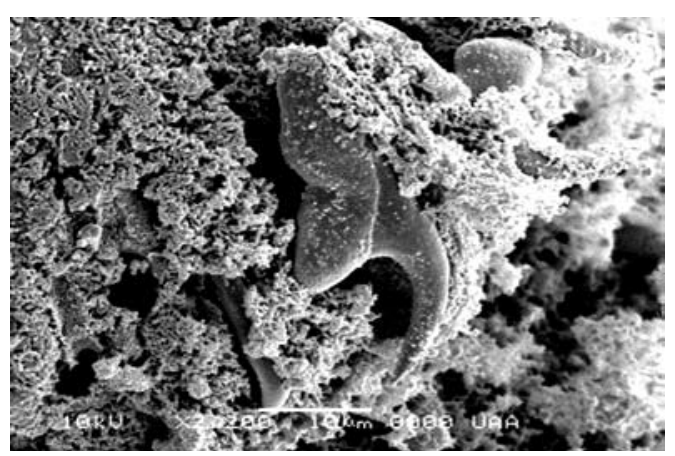

Fig. 7 Detalle de un gancho de la hilera superior del escolex de E. granulosus. MEB.

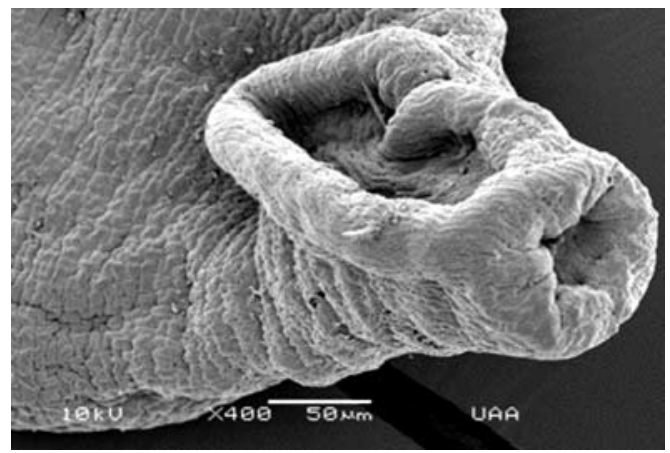

Fig. 8 "Cicatriz" al desprenderse un proglótido grávido del estróbilo de E. granulosus. MEB.

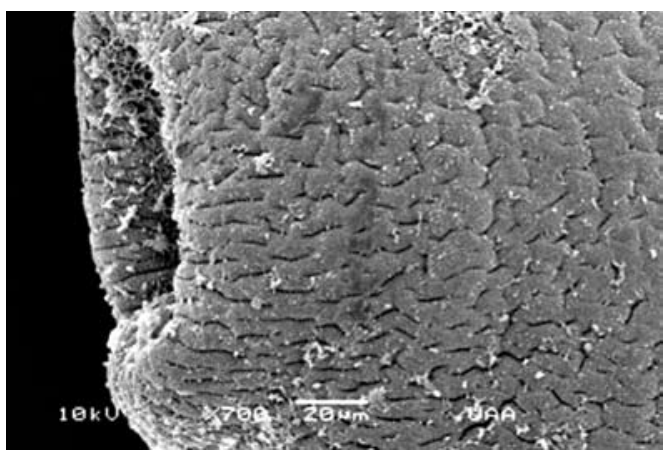

Fig. 9 Superficie de un proglótido de E. granulosus, con aspecto de mucosa intestinal. MEB. 


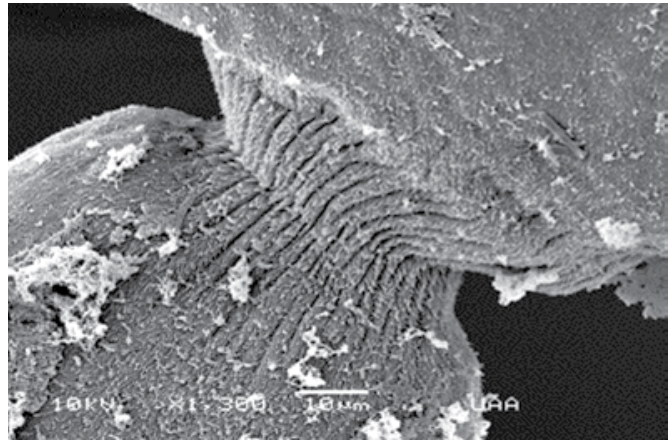

Fig. 10 Detalle de la unión de dos proglótidos de E. granulosus con pliegues. En la superficie se observan vellosidades más alargadas. MEB.

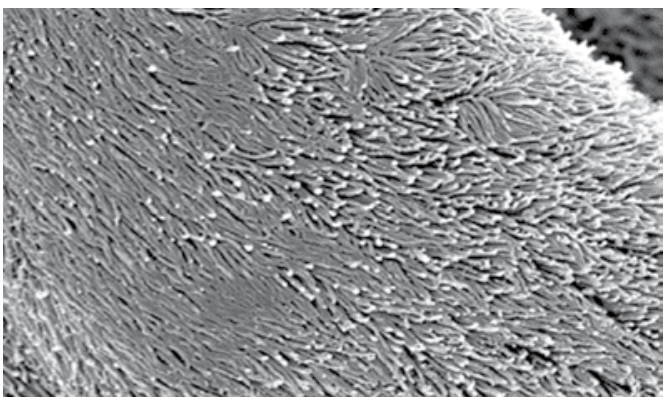

Fig. 11 Superficie de un proglótido de E. Granulosus, llama la atención su cubierta vellosa.

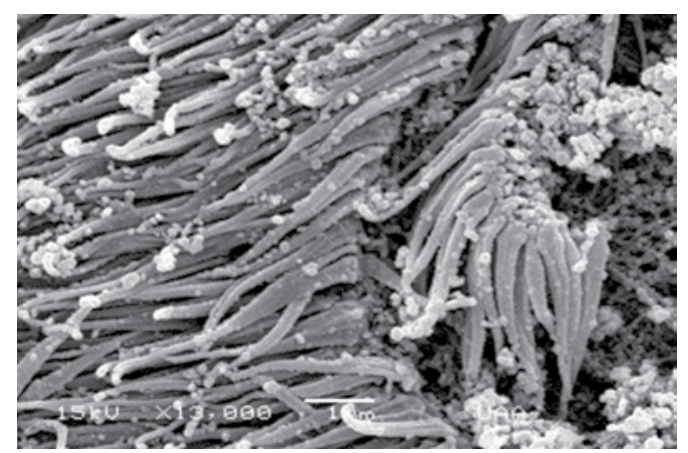

Fig.12 Acercamiento de la superficie de E. granulosus, mostrando las vellosidades que lo recubren con aspecto de intestino. $M E B$ Gómez-Torres

\section{Condusiones}

Sin duda alguna el microscopio electrónico de barrido es una herramienta innovadora y sumamente importante para la identificación experimental de organismos micrométricos como lo es el E. granulosus. Es de destacar que estas imágenes demuestran todas las estructuras ya conocidas por otros métodos y que probablemente las captadas por MEB en la superficie del gusano de este trabajo confirman el orden estructural que le permite tomar sus nutrientes del medio que lo rodea a través de estos (microvilli), ya que el platelminto carece de tubo digestivo. En la figura 7 correspondiente al gancho se usa morfometría para identificación de especie.

\section{Bibliografía}

1 Ancha PN. Hidatidosis; zoonosis y enfermedades transmisibles comunes al hombre y a los animales. $2^{a}$ ed. Pub. Científica Num 503, Washington DC Pub Organización Panamericana de la Salud, pp734 54, 1992

2 Ivanisevich O, Rivas C. Equinococo sis hidatídica. Buenos aires. Latle, 1962

3 Beaver $P$, Jung R, Cupp E. Parasitología clínica $2^{\mathrm{a}}$ edicion. 1986. Salvat pp 571-572

4 Rosales F, Gavidia C, Lopera LB. Obtención de Echinococcus granulosus en caninos infectados experimentalmente con protoescólices de quistes hidatídicos. Rev Inv Vet Perú. 2008; 19 (1): 37-42.

5 Lymbery A, Hobbs R, Thompson R. The dispersion of Echinococcus granulosus in the intestine of dogs. J Parasitol. 1989; 75: 562-570.
6 Saad M. Experimental transmission of hydatid infection from camels and cattle to dogs. Ann Trop Med Parasitol. 1987; 82(4): 363-365.

7 Romero-Cabello R, Jalak-Cababie M. Hidatidosis hepática. Reporte de un caso. Rev. Mex. Patol. Clin. 1987; 34: 85-87.

8 Biagi FF, Garza S. La Hidatidosis subcutánea en la Republica Mexicana. Rev. Fac. Med. 1963; 5:31116.

9 Mazzoti L. Encuesta sobre la frecuencia del quiste hidatídico en México. Rev. Inst. Salubr. Enf Trop Mex. 1959; 19:309-16.

10 Gómez-Torres JR. Quiste hidatídico. Reporte de un caso en el estado de Aguascalientes. Archivos del ISEA. 1992; 7(2);335-337.

11 Galindo M, González J, Galanti N. Echinococcus protoescolex formation in natural infection. Biol. Res. 2002; 35:365-371. 